doso en la 1

ar ejemplos a

is funcionalidac uso, dependiende encarnan los conceptos detr por e $\Lambda$ influ
$\mathrm{Pe}$ infin:

Las formas $d r$ oceso de sig ialidad .

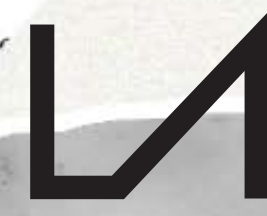

R E V I S A
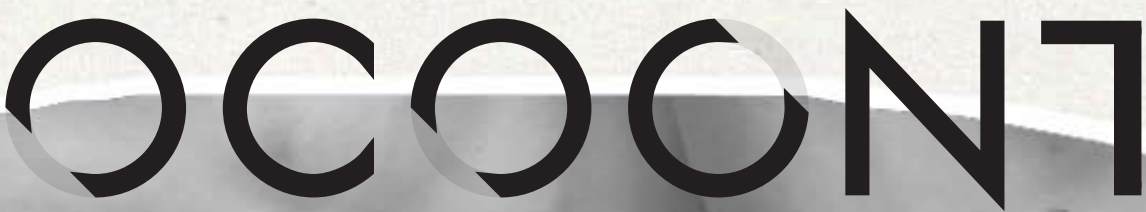

D $E$

No $6 \cdot 2019 \cdot$ ISSN 2386-8449

"El producto del diseñador es un proyecto, el estado previo de un objeto", Entrevista con Norberto Chaves, por Fernando Infante

El papel de la investigación y la teoría en diseño. Una conversación abierta, por Fernando Infante y María Jesús Godoy

UT PICTURA POESIS

Abandonar la escritura. Poesía experimental y manifiesta, Ignacio Gómez de Liaño

PANORAMA: FILOSOFÍA DEL DISEÑO Sección coordinada por Fernando Infante y María Jesús Godoy

Pensar el diseño, Fernando Infante y María Jesús Godoy (Coordinadores)

TEXTOS INVITADOS

Estatus y estado del điseño más allá del objeto, Pedro Medina Reinón

Mar de Nubes, Cuerpo de Cristal, Dionisio González

ARTÍCULOS

Understanding Design Aesthetics beyond Functional Beauty accounts, Lucía Jiménez Sánchez

Estética y diseño industrial: debates y controversias, Joan M. Marín

Del ornamento al delito. El diseño y la sociedad en Charles Baudelaire y Adolf Loos, Jorge López Lloret

When is Architecture not Design? Saul Fisher

Diseño y habitabilidad: una aproximación basada en los lenguajes de patrones, Antonio Hidalgo Pérez

Marcel Breuer: un diseñador global. Experiencias en el ámbito de la vivienda prefabricada, Salvador J. Sanchis, Ignacio Peris y Pedro Ponce Diseño y artes escénicas: el papel de Oskar Schlemmer en Das Triadische Ballett y la actualidad de la Bauhaus, Milagros García Vázquez Lo performativo en prácticas de arte y diseño actuales vinculadas a procesos de innovación social. El caso de La Venezia che non si vede y de La borda, Tània Costa Gomez

Articulaciones de la estética y el diseño. El caso de la evaluación a partir de la investigación dirigida en la carrera de diseño escénico de la Universidad de las Artes de Cuba, Mara Rodríguez Venegas y Xiomara Romero Rojas

SUPLEMENTO

El diseño, la ciudad y un lápiz de labios, Mercedes Espiau, Mar García Ranedo y Alejandro Rojas mas. 


\section{UつCつCNTE}

No $6 \cdot 2019 \cdot \operatorname{ISSN} 2386-8449 \cdot$ DOI 10.7203/LAOCOONTE.5.15381

https://ojs.uv.es/index.php/LAOCOONTE/index

COORDINACIÓN EDITORIAL

Anacleto Ferrer (Universitat de València)

Francesc Jesús Hernàndez i Dobon (Universitat de València)

Fernando Infante del Rosal (Universidad de Sevilla)

SECRETARÍA DE REDACCIÓN

Lurdes Valls Crespo (Universitat de València)

Vanessa Vidal Mayor (Universitat de València)

COMITÉ DE REDACCIÓN

Tamara Djermanović (Universitat Pompeu Fabra), Rosa Fernández Gómez (Universidad de Málaga), Anacleto Ferrer (Universitat de València), Ilia Galán (Universidad Carlos III), Ana María García Varas (Universidad de Zaragoza), María Jesús Godoy (Universidad de Sevilla), Fernando Infante del Rosal (Universidad de Sevilla), Miguel Ángel Rivero (Universidad de Sevilla), Miguel Salmerón (Universidad Autónoma de Madrid), Gerard Vilar (Universitat Autònoma de Barcelona).

COMITÉ CIENTÍFICO INTERNACIONAL

Rafael Argullol* (Universitat Pompeu Fabra), Luis Camnitzer (State University of New York), José Bragança de Miranda (Universidade Nova de Lisboa), Bruno Corà (Università di Cassino), Román de la Calle* (Universitat de València), Eberhard Geisler (Johannes Gutenberg-Universität Mainz), José Jiménez* (Universidad Autónoma de Madrid), Jacinto Lageira (Université Paris 1 Panthéon-Sorbonne), Bernard Marcadé (École Nationale Supérieure d'Arts de Paris-Cergy), Elena Oliveras (Universidad de Buenos Aires y Universidad del Salvador), Pablo Oyarzun (Universidad de Chile), Francisca Pérez Carreño* (Universidad de Murcia), Bernardo Pinto de Almeida (Faculdade de Belas Artes da Universidade do Porto), Luigi Russo (Università di Palermo), Georges Sebbag (Doctor en Filosofía e historiador del surrealismo), Zoltán Somhegyi (University of Sharjah, United Arab Emirates), Robert Wilkinson (Open University-Scotland), Martín Zubiria (Universidad Nacional de Cuyo). *Miembros de la Sociedad Española de Estética y Teoría de las Artes, SEyTA

\begin{tabular}{lll}
\hline DIRECCIÓN DE ARTE & REVISIÓN DE TEXTOS & TRANSCRIPCIÓN DE TEXTOS \\
El golpe. Cultura del entorno & Antonio Cuesta & Álvaro G. Serna
\end{tabular}

(cc) BY Excepto que se establezca de otra forma, el contenido de esta revista cuenta con una licencia Creative Commons Atribución 3.0 España, que puede consultarse en http://creativecommons.org/licenses/by/3.0/es/deed.es

EDITA

\section{SEyTA.}

CON LA COLABORACIÓN DE

\begin{tabular}{|c|c|c|c|}
\hline $\begin{array}{l}\text { VNIVERSITAT } \\
\text { B VALENCIA } \\
\text { Institut te Creativitat } \\
\text { | |nnovacions Educatives }\end{array}$ & $\begin{array}{l}\text { VNIVERSITAT } \\
\text { IE ÖVALENCIA Departament de Filosofia }\end{array}$ & 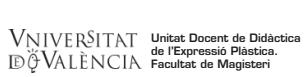 & \\
\hline $\begin{array}{l}\text { DEPARTAMENTO DE ESTÉTICA } \\
\text { E HISTORIA DE LA FLLOSOFIA }\end{array}$ & $\frac{\text { UAW }}{\frac{\text { UNIVRSSIDAD AUTONOMA }}{\text { DE MADRID }}}$ & $\begin{array}{l}\text { Universitat Autònoma } \\
\text { de Barcelona }\end{array}$ & $\begin{array}{l}\text { VNiVERSiDAD } \\
\text { Departamento de Filosofia, Lógica y Estética }\end{array}$ \\
\hline
\end{tabular}

LAOCOONTE aparece en los catálogos: 


\section{LつCつCN7E}

"Cuanto más penetramos en una obra de arte más pensamientos suscita ella en nosotros, y cuantos más pensamientos suscite tanto más debemos creer que estamos penetrando en ella".

G. E. Lessing, Laocoonte o los límites entre la pintura y la poesía, 1766.

Vo hay cól.

létodo, de pen.

:ión en general. Ith

zar la forma para el $\mathrm{n}$.

eptual por las orígenes

la, el objeto, la exposición

storia, porque existe en el $\mathrm{m}$

das sus raíces. Desde alli cc _. panoram

n conceptual y donde el émencia del con 'iseñado, como es el a al objeto y el di $\begin{array}{ll}\text { igen } \mathrm{de}^{\text {to }} \text { la inmer } & \text { tolvidada, o comc } \\ \text { trozo de madera ar }\end{array}$ a manera dorm comunicar ene nundo. Seguin? sngo en manos te el método $C$ les. A partir c teria prima $\mathrm{p}_{\mathbf{c}}$

'xto se puede:

¿ño, en proyea

amientos de $\mathrm{u}$

a conscie-

.)

en la publicación jue "plos de la impor te las nalidades porqu ura un ${ }^{2}$ diendo de qui zenerar $\mathrm{u}$ ción de nr? lne

in-

n-

is.

le http:,

le crear visualidades. A partir de.

ellas la propia materia prima para un en que desde un texto se puede generar $u_{11}$ i

Pensar en diseño, en proyección de nue

posibles comportamientos de una colecti

presente como una consciencia del hecho que estamos elaborando, significac

nuestro entorno (..)

Cardoso, R. C. Rafael. (2014). Design para um mundo complexo. Sãc asil: Cosac Naify. 


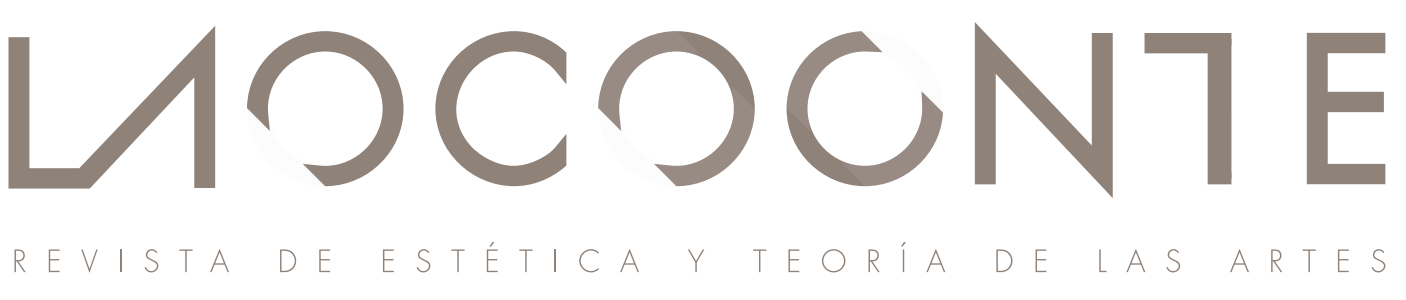

$\mathrm{N}^{\circ} 6 \cdot 2019$

PRESENTACIÓN

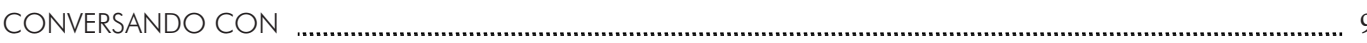

"El producto del diseñador es un proyecto, el estado previo de un objeto", Entrevista con Norberto Chaves,

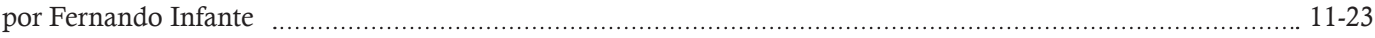

El papel de la investigación y la teoría en diseño. Una conversación abierta, por Fernando Infante

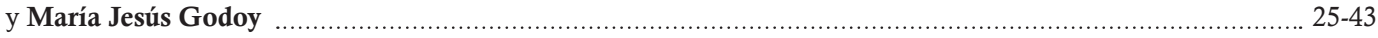

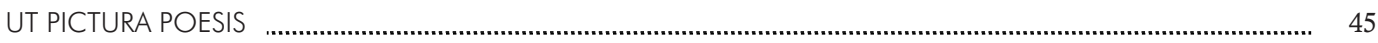

Abandonar la escritura. Poesía experimental y manifiesta, Ignacio Gómez de Liaño ................................................ 47-95

Imágenes de Laocoonte n. 6, de Isadora Gonzaga ................................................................................................... 96-97

PANORAMA

FILOSOFÍA DEL DISEÑO

Pensar el diseño, Fernando Infante y María Jesús Godoy (Coordinadores) .............................................. 101-105

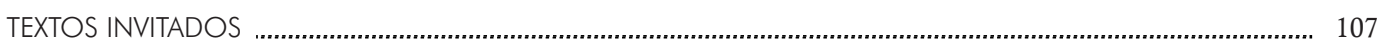

Estatus y estado del diseño más allá del objeto, Pedro Medina Reinón . ................................................... 109-125

Mar de Nubes. Cuerpo de Cristal, Dionisio González .............................................................................. 127-133

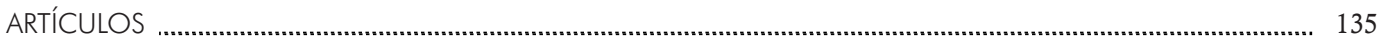

Understanding Design Aesthetics beyond Functional Beauty accounts, Lucía Jiménez Sánchez ................. 137-149

Estética y diseño industrial: debates y controversias, Joan M. Marín _...................................................... 150-164

Del ornamento al delito. El diseño y la sociedad en Charles Baudelaire y Adolf Loos, Jorge López Lloret ... $165-182$

When is Architecture not Design? Saul Fisher ……............................................................................. 183-198

Diseño y habitabilidad: una aproximación basada en los lenguajes de patrones, Antonio Hidalgo Pérez ...... 199-215

Marcel Breuer: un diseñador global. Experiencias en el ámbito de la vivienda prefabricada,

Salvador José Sanchis, Ignacio Peris y Pedro Ponce

Diseño y artes escénicas: el papel de Oskar Schlemmer en Das Triadische Ballett y la actualidad de la Bauhaus, Milagros García Vázquez

Lo performativo en prácticas de arte y diseño actuales vinculadas a procesos de innovación social.

El caso de La Venezia che non si vede y de La borda, Tània Costa Gomez

Articulaciones de la estética y el diseño. El caso de la evaluación a partir de la investigación dirigida en la carrera de diseño escénico de la Universidad de las Artes de Cuba, Mara Rodríguez Venegas

y Xiomara Romero Rojas

SUPLEMENTO 
Walter Gropius. La vida del fundador de la Bauhaus, Jorge Martínez Alcaide

¿Qué significa pensar la política desde la estética? Àger Pérez Casanovas

Ideologías estéticas en los orígenes de la pintura moderna, José Luis Plaza Chillón 300-303

Sobre a estética, Luis Carlos Pereira

Músicas populares. Sociedad y territorio: Sinergias entre investigación y docencia, Mar Aleixandre Badenes.

307-309

La necesidad de la mirada antropológica sobre la literatura, Pablo de Benito David

A propósito de Chandler, o la novela policíaca como tratado filosófico, Juan Evaristo Valls Boix

Videre aude!, Anacleto Ferrer

La inaplazable memoria del dolor y el sufrimiento, Antonio Notario Ruiz

La alargada sombra de la pintura, Raquel Baixauli

Sondear la maravilla, Juan Evaristo Valls Boix

... Y lo sabes, Marc Hernández Montoro

Arqueologías de la modernidad en las artes. Ensayo estético, Carlota Fernández-Jáuregui Rojas

Estética de la Instalación, Luis Cemillán Casis

La Herencia de otra época, María Jesús Godoy Domínguez

Del Theatrum Mundi al Gran Vidrio, Miguel Salmerón Infante

Imágenes de Isadora Gonzaga.

Fotografía de portada de Tamara Djermanovic intervenida por Isadora Gonzaga.

Los coordinadores de la sección Panorama: Filosofia del diseño agradecen

a Antonio Molina Flores su colaboración. 
ner.

llobj vidada, o de ma la publica. los de la im nalidades po ndientn $\mathrm{A}$ -
, la

que e.

usdño, si nn

ज. " da yara el mu tual y d

or enc or las orígenes un tmo, fía del diseño,

rpintero que'curra la forma de

eña Desige para un mundo complexo, de los bienes producidos por el hombre :tores subjetivos también influyen en su

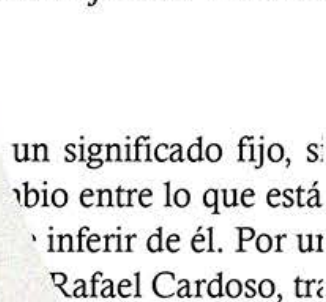

Rafael Cardoso, tri

No hay cómo no e método, de pensa 1, donde la reación en geperal. salizar la forma pa. rue amb ${ }_{\text {Snceptual por }}{ }^{1}$

$$
\text { -rola ol } n^{\prime}
$$

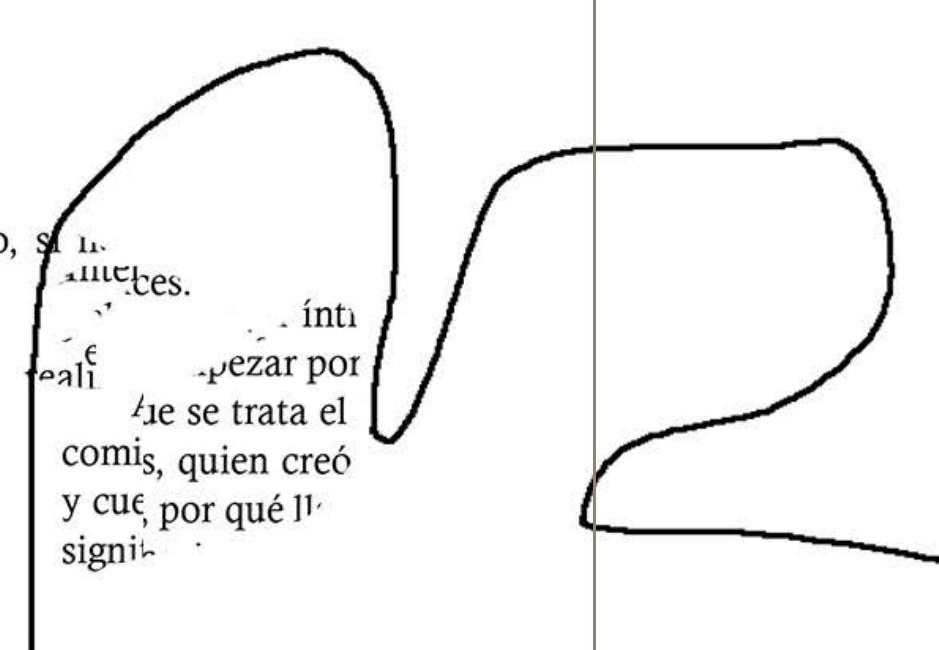

LOCOCNTE

PANORAMA: FILOSOFÍA DEL DISEÑO

Fernando Infante del Rosal y María Jesús Godoy Domínguez

(Coordinadores) 
No hay cómo no hablar de una filosofía del diseño, si no de izar la forma para el mundo sensible. Tción de formas y de la

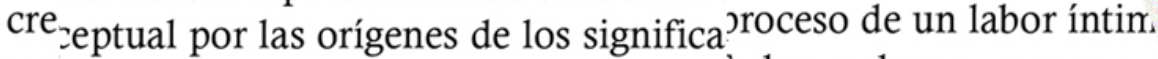

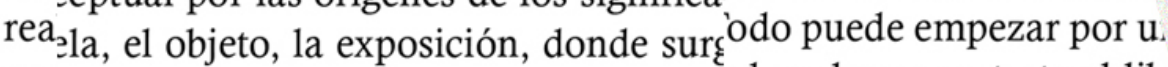

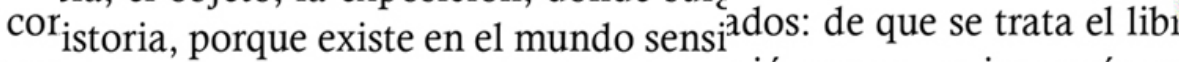
noładas sus raíces. Desde allí cojo el hilo gió, que es, quien creó y p su len conceptual y donde el está ubicado.ible o aún, por qué llama as

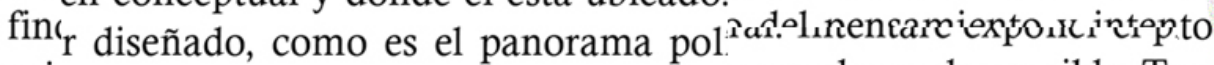
ori $_{\text {evolando la inmanencia del concepto. }}$ para el mundo sensible. Tc ce a s a forma al objeto y el diseñad ${ }^{\text {as }}$ orígenes de los significa)olo sob lengua olvidada, o como un cr la exposición, donde surg̨ido - nrocesr a un trozn de madera amnrfo le existe en el mundo sensin trai lengua olvidada,adas sus raíces. Desde allí cojo el hilona de ablo de procesc a un trozo de men conceptual y donde el está ubicado. perspectiva de lidoso en la publr diseñado, como es el panorama polndo ho, un camino diar ejemplos de levolando la inmanencia del concepto.: por una investigacióus funcionalidadı a forma al objeto y el diseñadı infl ro, el cuento, luso, dependiendı lengua olvidada, o como un $\mathrm{C} i^{\prime}$

qué, cuál e s nrecese a un trozo de madera amorfo

ata el 1

،en creó y pu.

or qué llama así, d

miento y intento a lles
- puede inferir de él. Por un in -reación ". (Rafael Cardoso, trad. 26 el ambiente que cerca el ol, especie de un danza en que ambos eleme iles son los símbolos que estso.

lmente, el contenido contextrño y hacer diseño, es antes de todo cue rna el papel de un tra o que toma la forma $\mathrm{d}^{\text {g }}$ gradual, donde la idea $\mathrm{do}_{\text {, las ideas, los relacioname }}$ danza en que ambos ropio proceso y también de r

'esign para un mundo liseñar, me planteé la cuesti' s bienes producidos por seño, es antes de tod prima eso me dá? Ejemp' es subjetivos también inf ble. Diseñar puede se ese texto, construyo el d

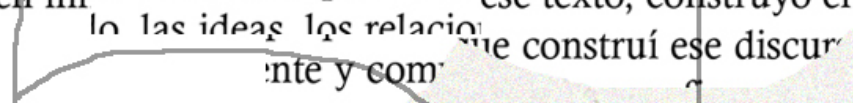

1 un significado fijo, sino que expresajue ${ }^{\dagger}$ mbio entre lo que está incrustado en Sre ¿de inferir de él. Por un lado, las form ". (Rafael Cardoso, trad. 2014)

rradual, donde la i’ 
- ormas y de rapo.

eso de un labor íntimo, un udo puede empezar por una inves 'dos: de que se trata el libro, el cu jió, que es, quien creó y por qué, ble o aún, por qué llama así, donı del pensamiento y intento a lle: Cual es el ambiente que cerca e ico. cuáles son los símholos aı

de una filosofía del diseño, si r e construcción de formas y de exponer el proceso de un labor í o sensible. Todo puede empezar los significados: de que se trata h, donde surgió, que es, quien creó y po mundo sensible o aún, por qué llama as cojo el hilo del pensamiento y intentc está ubicado. Cual es el ambiente que $\mathrm{g}$ anorama político, cuáles son los símb el concepto. Gradualmente, el conten y el diseñador encarna el papel de ur como un carpintero que toma la forr
LAU1 L11 glilla1. 111 n un sigizar la forma para e] ede inferifeptual por las orígt “. (Rafabla, el objeto, la exp istoria, porque exist y gradua adas sus raíces. De: en conceptual y do sible. $D$ : $r$ diseñado, como do, las icevolando la inman propio pri diseñar, a forma al prima e lengua olvi ese textos nrncesr a un trnzo ue construí ese discurso, he hecho de ara un reconfiguración de significado en para ilustrar... (en construccion) antiguas formas, es lanzar al mundo 1. La responsabilidad aquí se hace tamos elaborando, significados para

am mundo complexo. São Paulo,

1 agosto). Significado. Recuperado 1 br/significado/

\section{ИつCつCN7E}

PANORAMA: FILOSOFÍA DEL DISEÑO ARTÍCULOS 
- ormas y de rapon

aso de un labor íntimo, un udo puede empezar por una inves 'dos: de que se trata el libro, el cu rió, que es, quien creó y por qué, ble o aún, por qué llama así, donı del pensamiento $\mathrm{y}$ intento a lle Cual es el ambiente que cerca e ticn. cuáles son los símbolos a

de una filosofía del diseño, si r e construcción de formas y d $\epsilon$ exponer el proceso de un labor í o sensible. Todo puede empezar. los significados: de que se trata 1, donde surgió, que es, quien creó y po mundo sensible o aún, por qué llama as cojo el hilo del pensamiento y intento está ubicado. Cual es el ambiente que $q$ anorama político, cuáles son los símb lel concepto. Gradualmente, el conten y el diseñador encarna el papel de u somo un carpintero que toma la forr

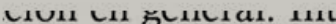
un signizar la forma para e] ambio eni ede inferieptual por las oríge n ". (Rafaəla, el objeto, la exp y gradua istoria, porque exist n danza adas sus raíces. De: en conceptual y do] sible. Dis $r$ diseñado, como do, las icevolando la inmanı ropio pri diseñar, $r$ ¥ forma al prima e lengua olvi

ese textos nrncesr a un trnzo ue construí ese discurso, he hecho de ara un reconfiguración de significado en para ilustrar... (en construccion) antiguas formas, es lanzar al mundo 1. La responsabilidad aquí se hace stamos elaborando, significados para

um mundo complexo. São Paulo,

1 agosto). Significado. Recuperado 1 $\mathrm{br} /$ significado/ 


\title{
Marcel Breuer: un diseñador global. Experiencias en el ámbito de la vivienda prefabricada
}

\author{
Marcel Breuer: a global designer. Research in the field of \\ prefabricated housing
}

\author{
Salvador José Sanchis Gisbert ${ }^{*}$, Ignacio Peris Blat ${ }^{* *}$ y Pedro Ponce Gregorio ${ }^{* * *}$
}

\section{Resumen}

En la nueva escuela de la Bauhaus se intentaba formar a una serie de artistas capaces de integrar los procesos creativos en un nuevo ideal de diseño. Marcel Breuer pertenece al primer grupo de arquitectos formados según estos principios, capaz de combinar la integración de los nuevos materiales, los procesos industriales y la fabricación en serie para la creación de nuevos proyectos. Este artículo pretende mostrar por una lado la gran polivalencia como diseñador de M. Breuer (mobiliario, interiores, arquitectura y urbanismo) así como recuperar sus investigaciones en el campo de la vivienda prefabricada, cuestiones ambas relacionadas con su singular formación y aprendizaje que marcaron su filosofía del diseño.

Palabras clave: Marcel Breuer; Bauhaus; arquitectura; filosofía del diseño; prefabricación.

\begin{abstract}
In the new school of the Bauhaus, an attempt was made to create a series of artists capable of integrating creative processes into a new design ideal. Marcel Breuer belongs to the first group of architects trained according to these principles, able to combine the integration of new materials, industrial processes and serial production for the creation of new projects. This article aims to show on the one hand the great versatility as a designer of M. Breuer (furniture, interiors, architecture and urban planning) as well as recovering his research in the field of prefabricated housing, issues both related to his unique training and learning that marked his philosophy of design.
\end{abstract}

Keywords: Marcel Breuer; Bauhaus; architecture; philosophy of design; prefabrication.

\section{Introducción}

Walter Gropius funda la escuela de la Bauhaus en 1919 siendo su director hasta 1928. Introduce a Marcel Breuer como profesor nada más completar sus estudios en 1924. No sólo fue uno de los primeros alumnos de una escuela tan singular sino que, además, participó activamente como profesor. Coincide con otros artistas como Kandinsky o Paul Klee, pintores, influenciados por Theo Van Doesburg, uno de los primeros responsables de la abstracción y de los desarrollos geométricos de la pintu-

* Salvador José Sanchis Gisbert, Universitat Politècnica de València, España. salsang1@pra.upv.es

** Ignacio Peris Blat, Universitat Politècnica de València, España. igpebla1@pra.upv.es

** Pedro Ponce Gregorio, Investigador libre, España.pedpongr@arq.upv.es

Artículo recibido: 30 de mayo de 2019; aceptado: 15 de octubre de 2019 
ra abordados en la Bauhaus; Laszlo Moholy Nagy, diseñador y fotógrafo; Josef A1bers, diseñador, fotógrafo, tipógrafo... constituyendo un equipo docente inmejorable. Compartían el ámbito profesional, docente y privado. Esta cercanía y el permanente contacto directo, generaba una transferencia de conocimientos entre las diferentes disciplinas muy enriquecedora. En consecuencia, M. Breuer entiende el diseño como un problema global, un ejercicio creativo multidisciplinar liberado de prejuicios y planteado desde una profunda abstracción.

M. Breuer escribe dos textos, a mediados de los años 30, en los que comienza a mostrar sus inquietudes teóricas y su particular posicionamiento en el campo del diseño. Por un lado el artículo titulado "On architectural and materials", publicado en la revista Circle en 1936, deja patente los nuevos postulados y las señas de identidad fruto de su formación en la Bauhaus. Es significativo en este sentido cuando, como corrección de un texto mecanografiado, ${ }^{1}$ en el apartado tercero, sustituye el término "modern movement in architecture" por "new architecture" "...la nueva arquitectura no consiste única y esencialmente en adquirir nuevos materiales ni en buscar nuevas formas, sino en adaptarse a una nueva mentalidad" (Breuer 1936: 1). También es especialmente relevante la conferencia titulada Where do we stand?, ${ }^{2}$ en la que expone sus ideas sobre los compromisos y relaciones de la arquitectura moderna con la arquitectura vernácula y el valor de lo tradicional.

Cuando viajamos, por ejemplo, nos interesamos intensamente por los lugares en los que la vida cotidiana de la población aún permanece imperturbada. Nada nos da mayor satisfacción que descubrir una obra artesanal heredada de padres a hijos, libre de la pompa pretenciosa y la inutilidad de la arquitectura del siglo pasado. Esto es algo de lo que aún podemos aprender, aunque naturalmente no en el sentido de la imitación, pues para nosotros sería improcedente y falso construir siguiendo una tradición nacional o un estilo antiguo... (Breuer 1938: 2).

En esa misma conferencia expone su entendimiento sobre la condición de los materiales con los que opera en el campo del diseño, “...la utilización de materiales tanto nuevos como tradicionales y la transformación de conceptos tradicionales en contemporáneos conducen a la generación de formas nuevas, lo cual no supone un retroceso sino una evolución..." (Breuer 1938:4).

Como vemos, M. Breuer está definiendo las claves de su manera de hacer. Estos textos podemos entender que culminan con la publicación de su monografía Marcel Breuer: Sun and Shadow. The Philosophy of an Architect. Este libro, el más importante de toda su carrera, se aborda como un ejercicio de diseño global, contando para su desarrollo con la colaboración de fotógrafos, pintores, diseñadores y arquitectos ${ }^{3}$ : se plantea como un proceso creativo multidisciplinar. Se organiza en cuatro partes. La primera y la cuarta, se titulan igual, Obras y proyectos, y recogen el trabajo de M. Breuer en dos etapas diferentes ordenadas cronológicamente. Las dos partes centrales del libro son escritos del propio M. Breuer. Se titulan, respectivamente, Principios y El arte del espacio. Contienen siete textos con las ideas que formulan su cuerpo teórico. En este caso no

\footnotetext{
https://www.aaa.si.edu/assets/images/collectionsonline/breumarc/fullsize/AAA_breumarc_204117.jpg

El título original es Wo stehen wir heute? Es una conferencia realizada en el Werkbund de Suiza en 1934. Fue traducida al inglés por el propio Marcel Breuer en 1938.

3 Alexis Brodovitch, Peter Blake, Ben Schnall, Robert Damora entre otros.
} 
se trata de explicar o presentar sus obras, como suele hacerse en un libro monográfico, sino que se pretende, mediante su obra construida, clarificar el pensamiento con el que se han acometido estos trabajos. Es una publicación absolutamente singular y extraordinaria, pues es extraño encontrar a un arquitecto que, más allá de exponer su obra, se esfuerce por explicar en esos años, su filosofía de diseño.

\section{De la butaca Wassily al edificio de la unESCo. Desarrollo profesional en etapas}

M. Breuer permanece en Europa hasta que en el año 1937 emigra a los Estados Unidos, donde se afincará definitivamente. Vivió y trabajó en diferentes países como Alemania, Inglaterra, Francia, Estados unidos, en un proceso de formación y crecimiento sensible en cada localización. Resulta adecuado recorrer estas etapas para terminar de comprender la dimensión del personaje. Así encontramos una primera etapa europea hasta 1937, en la que encontramos un trabajo principal centrado en el diseño de mobiliario con pequeñas incursiones en el campo de la arquitectura por falta de oportunidades, en gran parte debido a la profunda inestabilidad en la que se vive en Europa durante casi todos esos años. Destaca también su labor como docente en la Bauhaus, una cualidad muy importante para el proceso de comunicación del diseño.

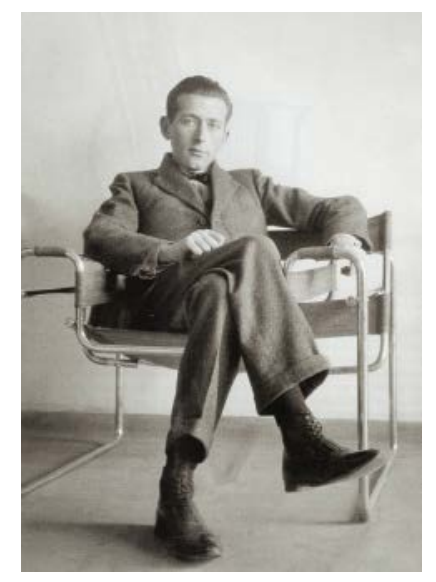

Figura 1. M. Brever sentado en la butaca B3 Wassily 1927

Con menos de treinta años es capaz de proponer dos sillas que son, hoy en día, auténticos iconos del diseño de mobiliario como la butaca B3 Wassily (Figura 1), y la silla en voladizo B32, Cesca. Ambos diseños se basan en el hábil entendimiento y manipulación de las cualidades del tubo de acero cromado. Estos primeros trabajos, propios de un diseñador industrial, le dotan de unas cualidades en su relación con el material, de gran influencia para el resto de su desarrollo profesional. En 1930 se encarga de desarrollar las propuestas de mobiliario y arquitectura para la exposición del Werkbund de París (Figura 2). Es uno de los grandes responsables en el logro de la introducción del diseño industrial en el ámbito particular del mobiliario de las viviendas. El compromiso con el usuario se evidencia a través de un estudiado confort. Muestra de ello son los mecanismos de suspensión para el diseño de sillas, así como la utilización de materiales como la madera cuando se encuentran en contacto directo con el cuerpo. 


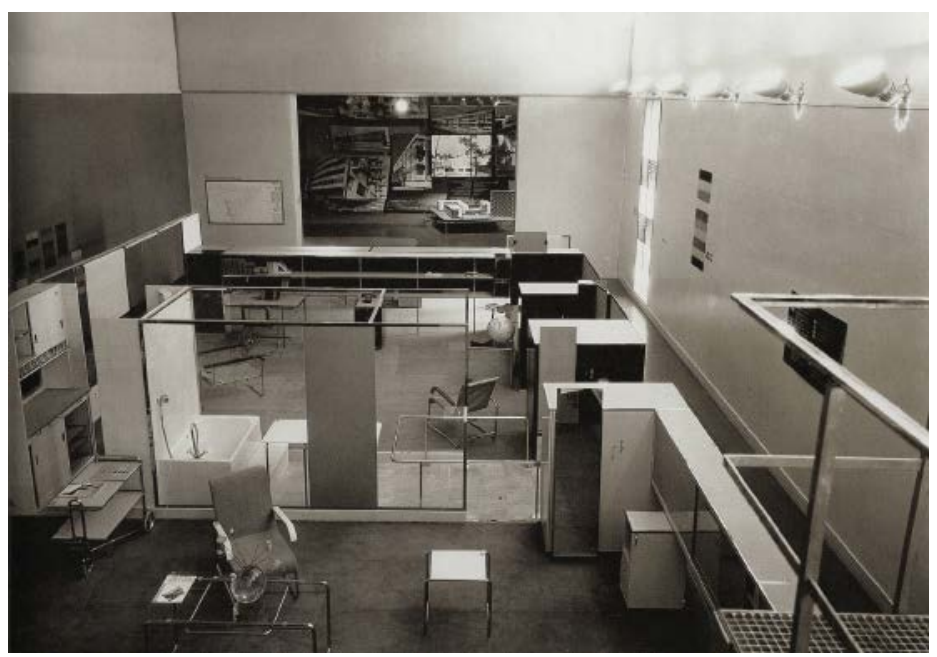

Figura 2. Exposición del Werkbund, París 1930

Sus únicas obras construidas en estos años son una vivienda unifamiliar, la casa Harnischmacher, en Wiesbaden en 1932 y los apartamentos Dordenthal, en Suiza en 1934. Son obras abordadas de un modo global donde los binomios alojamientoespacio y amueblamiento-usuario, forman un conjunto íntimamente asociado. Quedan diferentes proyectos no construidos entre los que destacamos, por su interés espacial y planteamiento estructural, los bloques de apartamentos Spandau-Haselhorst (Figura 3) y el hospital Elberfeld (Figura 4). Son ejemplos que muestran, además de su interés por los sistemas en voladizo, su gran versatilidad como proyectista, enfrentándose por primera vez a la escala urbana.

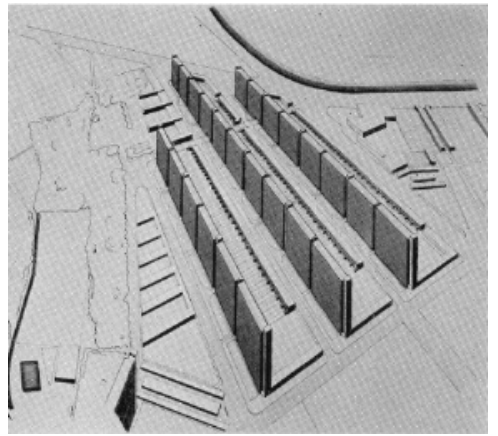

Figura 3. Spandau-Haselhorst. 1928

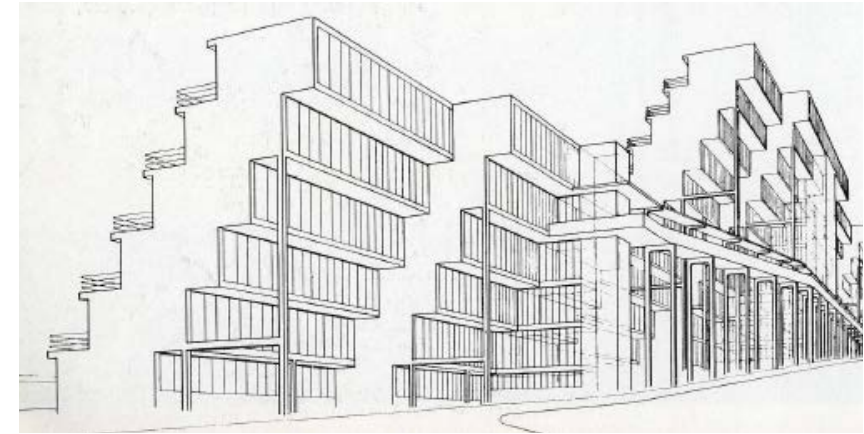

Figura 4. Hospital de Elberfeld. 1928

Siguiendo esta línea, resulta de mayor interés, por su ámbito urbano y de espacio público, la propuesta para la Unidad Vecinal del Futuro de Londres ${ }^{4}$ (Figura 5), en colaboración con F.R.S. Yorke, realizada durante su estancia en Inglaterra. La implantación de la edificación resuelve diferentes usos y genera, a través del estudio

4 El título original es "Civic Center of the Future". Si bien podemos encontrarlo traducido como Ciudad del Futuro en muchos textos, parece más adecuada la interpretación propuesta, Unidad Vecinal, puesto que realmente es, como explica M. Breuer en sus textos, una célula, un barrio, cuya repetición conformaría el tejido urbano, la ciudad. 
de su propia geometría y de su disposición, una propuesta de entendimiento sobre el espacio público. Cede todo el plano del suelo para el habitante resultando un espacio continuo. Dispone bloques de 12 alturas, siempre abiertos y transitables en planta baja. Su posición enfrentada N-S en el caso residencial, con extensión de hasta $210 \mathrm{~m}$. de largo, o más aislados y en forma de Y para el uso oficina, de unos $130 \mathrm{~m}$. de largo, favorecen la aparición de ámbitos de carácter más estático, a modo de plazas, dentro del conjunto. La idea de plaza resulta todavía más evidente en la solución para el centro comercial. Un edificio más compacto que dispone de un espacio central, con identidad propia, acotado por una edificación escalonada.

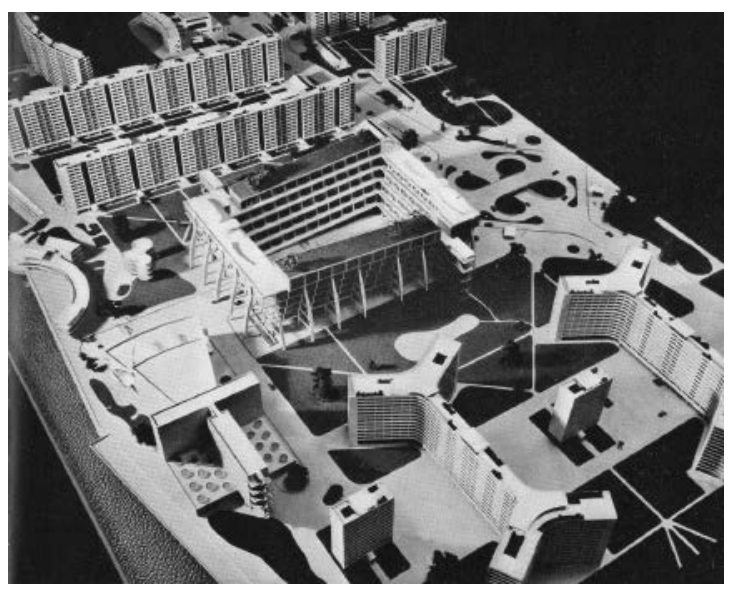

Figura 5. Civic Center of the Future. Londres. 1936

La etapa americana comienza en 1937 cuando W. Gropius le consigue un puesto como docente en la Universidad de Harvard. Su segundo período de docencia finaliza voluntariamente en 1947. Son años centrados en el campo residencial principalmente donde la vivienda es su principal campo de trabajo. Por un lado, atiende encargos de viviendas unifamiliares que compagina con el estudio e investigación de prototipos prefabricados y sus sistemas binucleares. La exposición de un prototipo suyo de bajo coste en el jardín del MoMA en 1949 le supone un gran reconocimiento y además logra en 1952 el encargo del proyecto para la sede de la Unesco en París ${ }^{5}$ (Figura 6).

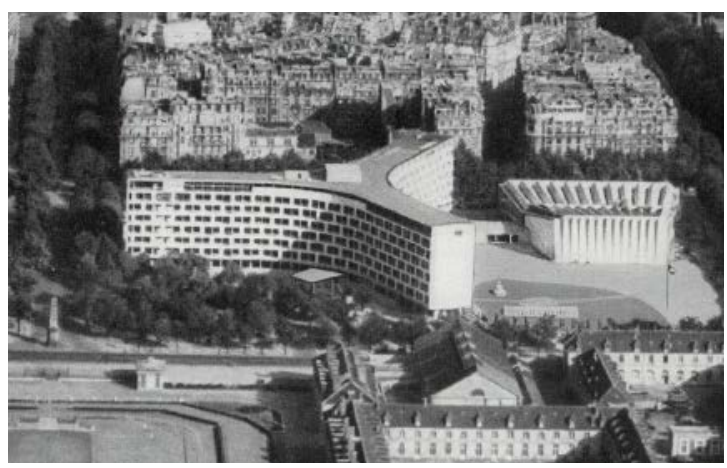

Figura 6. Vista de la sede de la Unesco desde la Torre Eiffel

5 Este encargo, realizado por una comisión de arquitectos entre los que se encuentra Le Corbusier y W. Gropius, lo realiza junto a Pier Luigi Nervi y Bernard Zehrfuss. 
Todos estos trabajos se recogen en la publicación de su monografía en 1955, comentada anteriormente, titulada "Marcel Breuer: Sun and Shadow. The Philosophy of an Architect" (Figura 7). Constituida como un auténtico manifiesto, cierran una etapa de cambio que le colocan en una nueva dimensión.
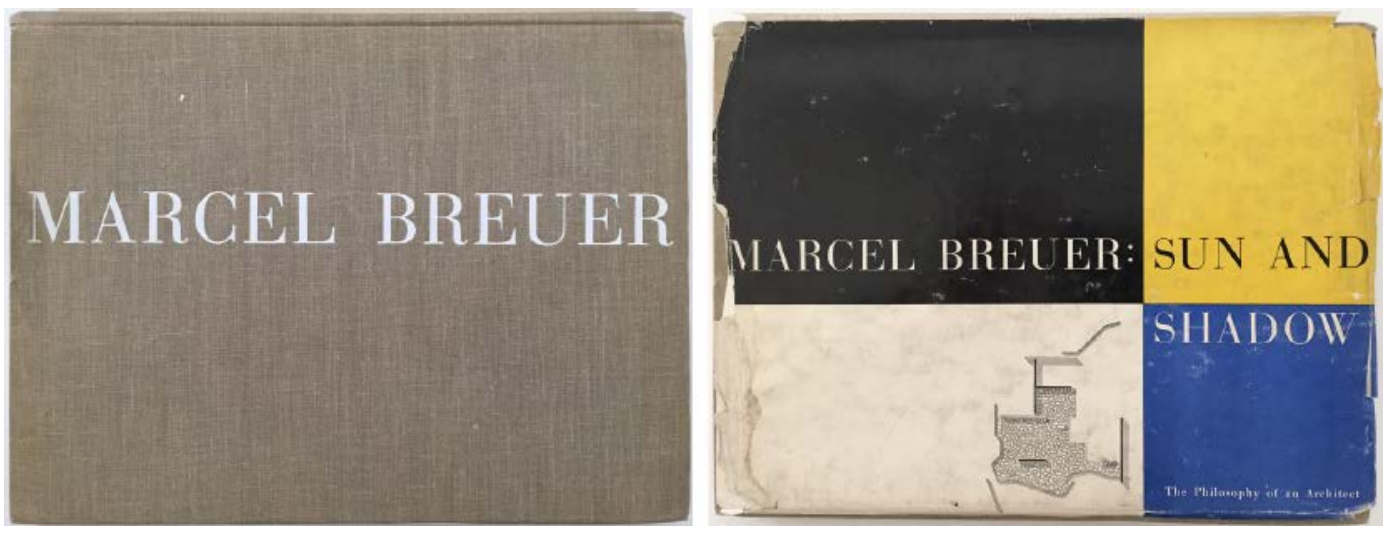

Figura 7. "Marcel Breuer: Sun and Shadow. The Philosophy of an Architect".

Portada libro entelada y sobre cubierta en papel a color diseñada por A. Brodovitch

A partir de 1955, su indudable nivel como arquitecto y diseñador, así como su alta capacidad de trabajo en equipo, le abren una nueva etapa internacional que culminará con su retiro efectivo en 1976 por problemas de salud. Este reconocimiento profesional le facilita el acceso a encargos por todo el mundo. En ellos, podrá experimentar con soluciones que lleva años elaborando en el campo de la prefabricación, la producción en serie y la estandarización. Se iniciaron en el campo del diseño del mobiliario, con la butaca Wassily, recorrieron el ámbito residencial y experimentan un nuevo cambio de escala con el edificio de la Unesco de París. De la mano de Pier Luigi Nervi descubre las enormes posibilidades de un material como el hormigón, versátil y económico que empleará principalmente para atender la nueva escala de estos proyectos. Incorpora soluciones prefabricadas en hormigón para sus Edificios institucionales, Conventos, Universidades, Edificios comerciales, Industriales, Oficinas centrales de grandes multinacionales... el número y diversificación es ingente. Si bien nunca abandona el campo de la vivienda, ahora se asocia con encargos de alto presupuesto y gran tamaño.

\section{El campo de la vivienda en M. Breuer. Estudios para la prefabricación y producción en serie \\ El estudio de las viviendas prefabricadas en M. Breuer se fundamenta en diversos motivos. Por un lado, en el libro Marcel Breuer: Sun and Shadow. The Philosophy of an Architect, su monografía-ideario más importante, los principales trabajos que se recogen están referidos a la vivienda. Es uno de los arquitectos que más esfuerzo ha dedicado a este tema. Desde que llega a los Estados Unidos se centra en el desarrollo de propuestas relacionadas con el habitar en múltiples facetas. Se le atribuyen 98 propuestas residenciales, ${ }^{6} 84$ de las cuales se plantean antes del año 1956.}

6 Atendiendo a las investigaciones realizadas por Joachim Driller con motivo de su tesis doctoral y recogido posteriormente en la publicación Breuer houses. 
En términos de producción, estudió unidades vecinales de gran tamaño, propuestas urbanas, como el "Civic Center of the future" de 1936, "New Kensington Defense Housing" de 1941 o "Stuyvesant Six" en 1943, llegando a desarrollar la primera vivienda de bajo coste expuesta en el jardín del Museo de Arte Moderno de New York en 1949. En términos de diseño, algunos de estos trabajos comparten una serie de inquietudes e intenciones como son la atención prefabricación, empleando materiales tradicionales como la madera, el control de $\operatorname{costes}^{7}$ o el estudio de la función, buscando el máximo confort para sus habitantes, que llega a materializar con los estudios de las casas binucleares.

M. Breuer, tanto por la formación recibida e impartida desde sus inicios en la escuela de la Bauhaus como por su amplio e importante trabajo desarrollado en el campo del mobiliario y los procesos industriales asociados, experimenta, con las obras de arquitectura, un cambio de escala en relación a la prefabricación, la producción en serie y el control de los procesos constructivos. Este cambio se asocia a la mejora de los procesos y la reducción de costes, cuestiones fundamentales a contemplar por un buen diseñador. Constata el fuerte sentido constructivo que se muestra en sus obras.

Para sacar todo el provecho a un principio constructivo y estructural, se necesita pasión y lógica. Existe un alma de la construcción y un instinto para la ejecución. [...] Experimentar con una construcción es divertido y transmite la sensación de estar actuando creativamente. Aunque, evidentemente, esto no debería ser una acrobacia sino una exploración de lo posible (Jones 1963: 19).

En el libro Marcel Breuer: Sun and Shadow. The Philosophy of an Architect en la parte cuarta titulada "Part Four: Works and Projects" dedica un apartado específico dentro del campo de la vivienda colectiva, a los sistemas prefabricados como herramienta capaz para desarrollar este tipo de implantaciones. La modulación, el orden, la idea del ensamblaje y la construcción en seco, son aspectos que guardan con la prefabricación una profunda relación.

Así, en el campo de la prefabricación y producción en serie de viviendas, encontramos cuatro proyectos residenciales: Kleinmetallhaus (1925), BAMBOS (1927), Yankee Portable (1942) y Plas-2-Point (1943). Los dos primeros se desarrollan en Europa ligados a su etapa en la Bauhaus, en estos el material empleado era el acero. Los otros dos proyectos los desarrolla casi 15 años después durante su primera etapa en Estados Unidos, cuando todavía es docente en Harvard, y en ellos el material utilizado es la madera. Estas dos últimas propuestas se presentaron ante la National Housing Agency en Washington, D.C., incluso como alojamientos para ex combatientes, pero no llegó a formalizarse ningún contrato. El alto grado de investigación que en su formulación tienen estos proyectos nos hacen entender que es necesario su revisión y se expone a continuación.

Kleinmetallhaus, 1925-1926.

Los primeros proyectos que desarrolla con la idea de producirse en serie se

$7 \quad$ Estas variables eran muy tenidas en cuenta por la restricción en el uso de materiales, acero principalmente, debido a los períodos de Guerra en los que se encuentra inmerso el país, y eran una herramienta clave para cualquier diseñador 
remontan a su etapa en la Bauhaus. Seguramente en el momento en el que establece sus series modulares para los sistemas de armarios "cabinet", preparados para incorporar a la vivienda un mobiliario que se produjera en serie, empezó a rondarle por la cabeza la idea de extender una producción en la fábrica al campo de la vivienda.

El primer caso, las propuestas de la Kleinmetallhaus (Figura 8), también conocidas como small metal house, consisten en una serie de viviendas adosadas de dos alturas organizadas mediante dos bandas, una el estar-estudio, con la escalera incorporada y con doble altura, y otra banda con los servicios y los dormitorios en el nivel superior. Muestran el ideal de la Bauhaus de permitir desarrollar unos modelos en los que se combinen funciones como el habitar y el trabajo, dentro de una idea de colonia. Aunque encerrado en un solo volumen y con posibilidad de acceder hasta la cubierta, de algún modo el esquema de la vivienda guarda ciertas similitudes con su vivienda construida en Lincoln años después. El sistema propuesto hablaba de realizar un sistema modular de paneles de acero con un armazón estructural también de acero. En el año 1925 realiza una primera propuesta de viviendas para ser fabricadas en serie.

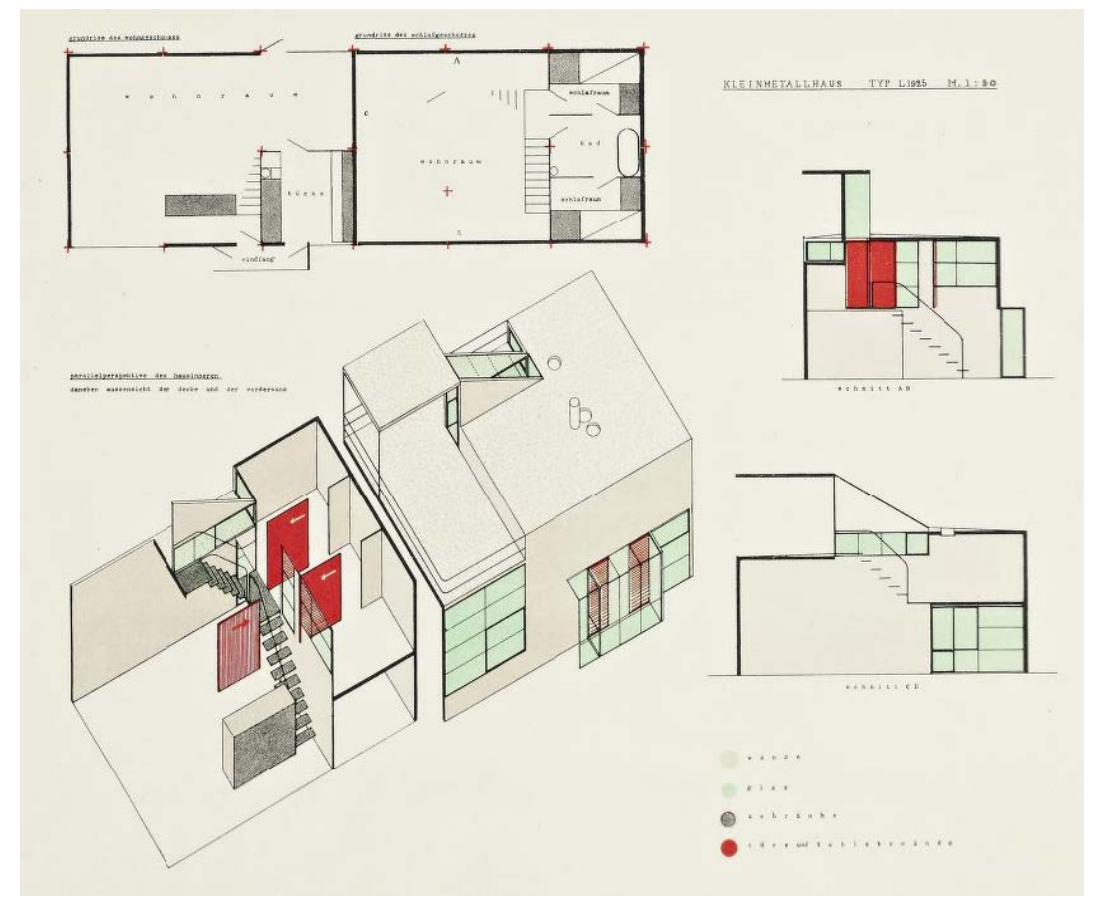

Figura 8. Kleinmetallhaus, 1926

Más adelante realiza unas modificaciones sobre el sistema que llama "small metal house" donde recoge hasta 6 posibilidades de distribución de la vivienda. A diferencia del primer dibujo general aparecido en 1925, en las axonométricas que acompañan las distintas plantas aparece una junta vertical que podría querer hacer referencia a un posible ensamblaje de los paneles de aproximadamente $3 \mathrm{~m}$. de altura. No se aprecia ninguna estructura adicional en la planta y parece que los cerramientos tienen cierto grosor, por lo que de alguna manera es de suponer que conforman a la vez cerramiento y estructura. 
Bambos, 1927.

Manteniendo y ampliando los principios que contábamos anteriormente, el programa de estas propuestas ahondaba todavía más en la idea de combinar funciones como la docencia y la convivencia. Se trata en este caso de una propuesta de viviendas para los "Jungmeister", jóvenes maestros de taller, que debía venir a completar en un escalón inferior, las viviendas que Gropius había diseñado para los maestros, las "Meisterhäuser" o villas para los maestros. Estas estaban totalmente alejadas del ideal de vivienda mínima que manejaba en esa época la Bauhaus y su construcción no estuvo exenta de polémica.

Las Bambos, viviendas cuya denominación obedecía a las iniciales de sus futuros ocupantes (Breuer, Albers, Meyer, Bayer, Meyer-Ottens y Schmidt), nunca llegaron a realizarse por problemas de financiación. La atención al programa y la función son singulares en este proyecto, agrupándolas de modo diferencial en área residencial, con luz de sureste y suroeste, área de trabajo, con luz de noreste, y las zonas de servicio como garaje, lavandería y trasteros. Existe información de 3 tipos distintos de combinaciones para la relación vivienda-taller. En las Bambos 1 el espacio del taller es independiente de la vivienda, formándose el conjunto a través de dos volúmenes adosados a distinta altura. Se encuentra elevado del plano del suelo y se accede a él mediante una escalera exterior. A ésta se accede directamente a cota de la calle. Con esta operación libera el suelo generando un espacio a cubierto lateral, a modo de patio o porche, y en planta alta recupera la cubierta como espacio de terraza. El cuerpo de la casa se organiza con un núcleo central de baños y cocina y dos dormitorios subdividibles a ambos lados. Sus dimensiones son generosas visualmente y $\mathrm{M}$. Breuer propone que se puedan compartimentar según las distintas necesidades de los usuarios mediante tabiques ligeros o mamparas textiles. Existe un pequeño lucernario inclinado para permitir que la zona central de servicios disponga de una buena iluminación y posible ventilación, demostrando la importancia que se le concede a estos espacios por M. Breuer. En las Bambos 2, la agrupación se realiza verticalmente, disponiendo la vivienda sobre el cuerpo del taller. En este caso al suroeste el espacio residencial, con el mismo programa que las Bambos 1, se termina con una terraza. En las Bambos 3 (Figura 9), la agrupación tiene un carácter extensivo y se basa en un sistema de bandas adosadas que tienen casa y estudio-taller. Este último se subdivide y se combina con la banda de vivienda que tiene anexa, formando en planta una especie de L. El esquema del espacio residencial también es distinto y se parte de una gran sala común y una banda de dormitorios-cabina de muy reducidas dimensiones. En consonancia a la planta propuesta, desarrolla una solución de huecos totalmente coherente con las necesidades de los espacios a los que sirve, y recurre al plegado de la cubierta para darle sentido mediante un sistema de lucernarios. Los dormitorios funcionan con una ventana rasgada alta continua dispuesta a noreste. La sala principal dispone de un gran hueco acristalado abierto a suroeste y a un patio. Por último, las zonas de talleres, disponen de un lucernario continuo de norte a suroeste, siendo opaco a la altura del plano de suelo, al igual que la zona de dormitorios. 


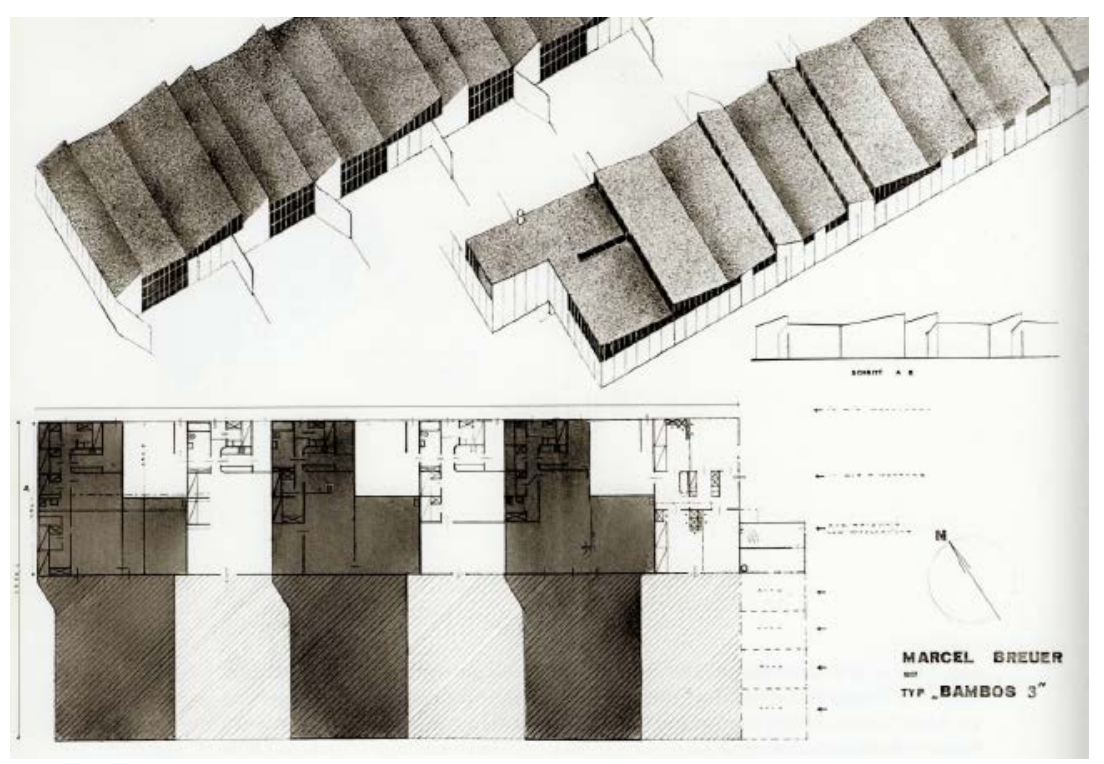

Figura 9. Bambos tipo 3. 1927

Con estas diferentes soluciones M. Breuer da una respuesta a sus ideales de lo que una casa moderna hoy debe contemplar. Por un lado, la vivienda vinculada al plano del suelo, facilita el acceso al espacio exterior desde todos sus lados y con máxima vinculación de las estancias. Por otro, la casa mirador, o casa belvedere, se eleva sobre el paisaje ofreciendo a sus habitantes mejores vistas y con una mayor sensación de libertad y de dominio de la naturaleza. Es interesante que la propuesta, a nivel constructivo y estructural, diera continuidad a los precedentes de la Kleinmetallhaus, pues parte de una comparación con el muro de piedra, que sostiene y aísla a la vez, pero necesitando importantes espesores para hacerlo adecuadamente. En contraposición, propone soportar y aislar mediante elementos independientes que forman parte de un mismo sistema. Se trata de paneles con entramado de estructura de acero que alojan en su interior los materiales aislantes y los elementos practicables como puertas o ventanas. Pretende, de este modo, transmitir una sensación de profunda ligereza condensando en una misma línea material, lo más fina posible, todas las funciones posibles en una envolvente tecnológicamente más compleja.

Los constructores medievales explotaban el arco de piedra hasta sus últimas posibilidades; un ingeniero moderno deseará también obtener el máximo de sus estructuras. Esta ambición es la raíz de los descubrimientos que, a su vez, repercuten en la economía. La estructura no es sólo un medio para resolver un problema, sino también un principio y una pasión (Breuer 1963: 19).

Es uno de los arquitectos que con más claridad ha entendido lo que ha supuesto la posibilidad de trabajar las estructuras no sólo a compresión como con la piedra, sino en flexión, con la incorporación del acero. "es un cambio tan radical que, por sí sólo, justificaría que la arquitectura se manifestase de una forma totalmente nueva" (Breuer 1963: 19).

Es probable que, la investigación previa desarrollada en Inglaterra para el fabricante de muebles en madera laminada Isokon, tenga gran influencia en las otras dos propuestas. 
Yankee Portable, 1942.

Este prototipo no construido, emplea paneles de madera en listones, a base de compuestos de madera "reciclada" o incluso con acabados plásticos (Figura 10). E1 sistema ofrecía algunas ventajas muy importantes, como era la implicación de un fabricante, Custance Brothers, que de algún modo respaldaba los diseños de M. Breuer. Esta propuesta de prefabricación se produce con un cambio de localización del arquitecto, ahora con residencia en Estados Unidos, y de material, proponiendo la madera como base de todo el proceso, como no podía ser de otro modo en Nueva Inglaterra. Los sistemas basados en el acero, que vimos anteriormente, permanecen para Europa. Sin embargo, comparten la idea de resolver el cerramiento y la estructura del mismo modo, a través de un panel auto portante de madera. El ensamblaje del propio panel, realizado sobre el suelo flotante que trabaja como una plataforma independiente formada también por paneles, junto a la cubierta, que en este caso ya presenta una ligera pendiente a ambas fachadas, arriostran y dan estabilidad a todo el sistema. La propuesta es desmontable y fácilmente transportable. El encuentro con el plano del suelo lo realiza a través de unos pequeños muros de hormigón que soportan un sistema de vigas de cimentación en madera paralelas a la fachada. Siempre aparecen ligeramente retiradas del frente, por la que logra mantener esa cierta sensación de ingravidez, apareciendo la caja flotando sobre el terreno. La cimentación es directa precisando para su instalación de una pequeña transformación y de terrenos favorables para asentarse.

La propuesta base adopta una profundidad fija de aprox. 7.20 m., 24', y propone, adoptando una agrupación en fila, establecer combinaciones posibles con viviendas de 1 a 3 dormitorios. En la práctica suponía que las viviendas podían crecer en función de su programa desde los $7.20 \mathrm{~m}$ hasta los $9.60 \mathrm{~m}$, lo que suponía en la práctica pasar de 6 a 8 paneles de aprox. $1.20 \mathrm{~m}$ de ancho. Los testeros en estos casos se trataban como medianeros y organizaba las estancias según dos bandas paralelas, agrupando el baño, siempre el mismo en todos los casos, y la cocina, que dispone de un segundo acceso e incorpora siempre un espacio para comer. Todas las estancias disponen de luz natural y ventilación directa al exterior. El centro geométrico de esta casa lo ocupa una chimenea para la calefacción. La sala principal se conecta con el exterior a través de un porche, con una solución que en planta ya ha propuesto anteriormente para la cabaña Chamberlain.

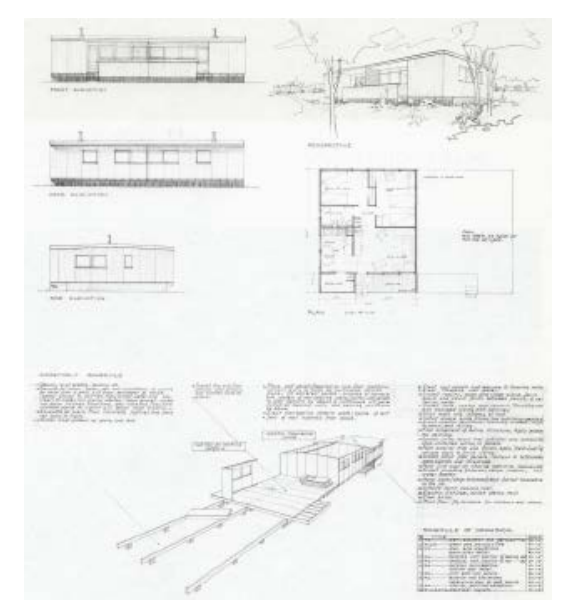

Figura 10. Yankee Portables 
Cuando la agrupación se basa en dos viviendas pareadas la profundidad aumenta hasta los $8.40 \mathrm{~m}$ y la distribución interior dispone el baño y la cocina en uno de sus testeros. Esta solución es la menos interesante de todas, puesto que parece que hace prevalecer un esquema de orden formal, reduciendo las posibilidades de la sala principal, el estar, a una relación idéntica a la que disfrutan las viviendas en hilera, beneficiándose poco de su condición aislada. En este esquema la distribución de áreas según su función es más clara, mostrándose como dos bandas que deslizan una junto a otra. En todas las soluciones la sala principal se ve obligada a soportar las circulaciones de acceso al resto de estancias, si bien en alguna de las propuestas por la posición más centrada del acceso, esta condición se evidencia menos. Las perspectivas que acompañan a los dibujos reproducen nuevamente esa búsqueda de relación con la naturaleza. Todas las viviendas, en sus agrupaciones, aparecen claramente arropadas por árboles de cierto porte. Es posible encontrar en ellos esbozos de caminos que se insinúan repeticiones en las agrupaciones, la presencia en segundos planos del vehículo como medio de transporte y, por supuesto, a sus habitantes disfrutando con una fuerte vinculación con el paisaje.

Plas-2-Point, 1943.

El sistema Plas-2-Point (Figura 11) debemos entenderlo como una evolución de las Yankee Portable compartiendo sus mismos principios, un sistema modular de paneles de madera. Aquí la cuestión más destacable es que apunta hacia una gran flexibilidad, que se puede aplicar desde el punto de vista de la vivienda y del emplazamiento, admitiendo en este último caso variaciones climáticas y geológicas. Respecto a la vivienda, el sistema estructural y constructivo propuesto, permite la modificación por parte del usuario de las distribuciones interiores, ofreciendo un alojamiento casi diáfano al poder compartimentar inicialmente sólo el baño y la cocina, generando nuevas estancias según las necesidades futuras. Respecto del emplazamiento y sus posibles variaciones climáticas, la libertad respecto a la posición y existencia de los cerramientos y particiones, le permite que pueda llegar a instalarse en lugares muy cálidos tropicales, eliminando los paneles de fachada y aumentando la superficie del porche. Por último, respecto del terreno, presenta un sistema de apoyo con el plano del suelo resuelto mediante dos únicos pies de muro de bloque de $1.20 \mathrm{x} 0.10 \mathrm{~m}$., 4'x8", que se encargan de transmitir las cargas de esta construcción al terreno. Esto resuelve, además de esa sensación de ingravidez con el terreno, el permitir desligar la construcción del tipo de terreno, siendo un sistema mucho más económico.

Para permitir esta manera de encontrarse con el plano del suelo y facilitar al usuario posibles modificaciones de su vivienda, plantea un sistema de dos grandes vigas centrales de madera, conectadas con un soporte en cada extremo, y que descansan sobre los pies de bloque. De estas vigas, tanto en el plano del suelo como en el del techo se disponen 7 vigas en voladizo conectadas a través de dos correas. El sistema precisa de dos paneles de 1.20 en cada fachada opuesta para arriostrar el conjunto, recogiendo las cerchas en su extremo final. No soportan ninguna carga y en realidad actúan atirantando tanto el plano del techo como el del suelo, que son los encargados de transmitir las tensiones a la viga central. Una de las distribuciones posibles que presenta se basan en el mismo sistema de doble banda o crujía habitable de dimensión total 24' x 24', como sucedía con la propuesta de las Yankee Portable de 1 habitación. En este caso ha girado 90 grados la posición del acceso y ofrece al frente de fachada la 
sala principal y la cocina, realizando un acceso entre ambos desde una pieza de porche como la que hemos ido viendo y que se encarga de realizar la transición con la calle. En cualquier caso realiza una desvinculación entre el porche y la sala principal o estar de la vivienda, ya que dispone de una pieza de almacenaje que fuerza al estar a una relación con el exterior a través de una ventana situada en la fachada opuesta.

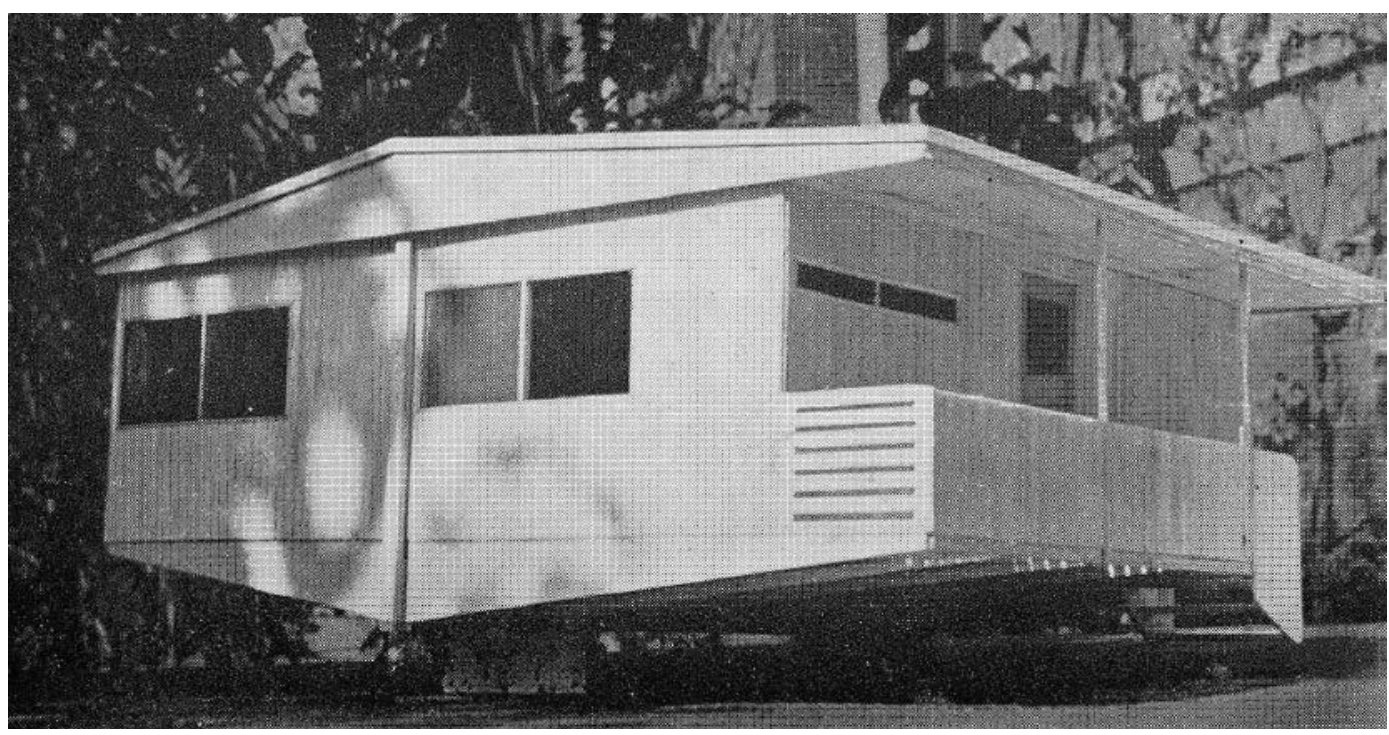

Fig. 11. Plas-2-Point

La planta tipo está pensada con tres frentes de fachada, uno vinculado a los accesos, y dos perpendiculares que resuelven la ventilación e iluminación de todas las estancias. La cuarta fachada es prácticamente ciega para permitir una agrupación de viviendas pareadas. La dotación de servicios higiénicos sigue siendo 1 estancia. La cocina incorpora de nuevo un pequeño espacio para comer. Es un tipo francamente ajustado de aprox. $52 \mathrm{~m}^{2}$ más el espacio del porche. El acabado de los paneles de madera laminada era mediante un revestimiento de resina plástica que debía aumentar la durabilidad de la madera. Permitiría un mantenimiento reducido sencillo e incluso incorporar el tema del color, particularizándolo para cada usuario. También mejoraba la impermeabilidad de la madera y su protección contra el exterior. El sistema propuesto era, en palabras de sus autores, un 30\% más ligero, un $70 \%$ más económico y ocupaba para el transporte entre un $30-40 \%$ menos que otros sistemas prefabricados del momento.

\section{Conclusiones}

M. Breuer se forma según los ideales de la Bauhaus a principios de los años 20 , en uno de los momentos más incipientes y revolucionarios de la arquitectura, y extiende aquellas ideas en el extranjero, desarrollando soluciones evolucionadas y adaptadas a los nuevos tiempos y necesidades sociales. En los Estados Unidos, con motivo de su llegada, existe la intención de presentarlo como uno de los arquitectos de sólida formación que salieron de la Bauhaus y que desarrollaron una labor completa en el mundo del diseño y la arquitectura. De este modo se respalda su capacidad para impulsar en este país su figura de arquitecto de la modernidad, capaz de hacer progresar la cultura arquitectónica en el nuevo continente. Este es uno de los aspectos 
que más interesan a Peter Blake, ${ }^{8}$ acérrimo luchador contra el término modernismo y del consecuente pensamiento reduccionista que intentaba asociar la arquitectura moderna en términos de estilo. P. Blake siempre pensó que, de algún modo, el término modernismo debería estar asociado a la idea de reforma, en los términos en los que desde la Escuela de la Bauhaus se intentaba transmitir.

$\mathrm{Su}$ indudable valor también ha sido reconocido por otros historiadores como Sigfried Giedion, para el que M. Breuer desarrolla los proyectos de los apartamentos Dolderthal en Zurich, o Henry Rusell Hitchcock. Este último aprovecha el ciclo de conferencias de Harvard del año 1938, en el cual M. Breuer presenta la traducción al inglés de su conferencia "Where do we stand?", para ahondar en esta idea de un diseñador global, un talento híbrido y casi un nuevo mesías.

Para dar el impulso decisivo a la arquitectura moderna hicieron falta dos temperamentos muy distintos; para nuestras ideas sobre la arquitectura moderna, el inflexible análisis intelectual de Gropius es un núcleo tan crucial, al menos, como la síntesis creativa de Le Corbusier, más difícil de expresar con palabras. Pero la continuación de la arquitectura moderna, sobre todo su evolución saludable en América, exige más bien la actuación de talentos híbridos, entre los que Breuer puede servir admirablemente de ejemplo (Hitchcock 1938: reel 5737).

M. Breuer es una de los diseñadores que mejor se adapta a las condiciones de los Estados Unidos. Por un lado es un fiel reflejo de la arquitectura moderna europea, con un perfil técnico desligado de ataduras formales, y demuestra la habilidad suficiente para filtrar de la arquitectura vernácula americana lo mejor de sus sistemas constructivos y de sus materiales, muy del gusto americano. Es un claro exponente formado según los ideales de la escuela de la Bauhaus. Representa la búsqueda incesante que persigue trasladar el ideal de la belleza que confía su razón de ser en los aspectos formales de apariencia y fruto de una inspiración, hacia el terreno de las relaciones constructivas y espaciales en un proceso de abstracción. Las propuestas de viviendas prefabricadas presentadas pueden constituir un hilo conductor que permite establecer las conexiones existentes entre su trabajo desarrollado en la Escuela de la Bauhaus y su etapa profesional posterior.

A lo largo de las diferentes etapas expuestas anteriormente se pueden extraer una serie de estrategias, intenciones y premisas en su tarea de diseño que podemos sintetizar en:

- Profunda relación entre material y diseño: cómo el diseño como proceso y producto (forma) está vinculado al material concreto y su adecuado conocimiento (materia).

- El diseño, proceso y producto, se hace cargo de variables como economía, transporte, dimensiones, peso... evidentes en la prefabricación.

- Su diseño muestra una relación convergente/divergente entre estructura y cerramiento, en el sentido constructivo, y también entre estructura y forma.

- Evolución en el diseño a partir soluciones anteriores o variaciones de las mismas. En las organizaciones de sus proyectos podemos detectarlo en el empleo de bandas, núcleos, sección, orientación, sustentación, agregaciones...

8 Arquitecto, crítico y editor de la revista Architectural Forum. Comisionado de Arquitectura y Diseño del Moma desde 1948. Redactó catálogo del Moma con motivo de la Exposición de la Casa en el Jardín, obra de M. Breuer. 
Demuestra con sus trabajos que la modernidad en la arquitectura nola aportaron los materiales o los procesos industriales de producción en serie, sino el cambio de actitud por parte de algunos arquitectos en la manera en que incorporaron en sus proyectos estos nuevos sistemas y materiales, una nueva filosofía del diseño.

\section{Bibliografía}

AAVV. 2003. Marcel Breuer diseño y arquitectura. Weil am Rhein: Vitra Design Museum. Bergdoll, B and Christensen, P., 2008. Home Delivery. Fabrication the modern dwelling. New York: Museum of Modern Art.

Blake, P. 1949. Marcel Breuer, architect and designer. New York: Museum of Modern Art. Breuer, M. 1936. On architectural and material, en Archives of American Arts, image id AAA_breumarc_5718_1323_001imageidAAA_breumarc_5718_1324_001,https:// breuer.syr.edu/xtf/view?docId=mets/33343.mets.xml;query=circle;brand=breuer.

— 1938. Where do we stand ?. Conferencia original de 1934 titulada Wo stehen wir heute? traducida al inglés por él mismo en 1938. https://www.aaa.si.edu/ collections/marcel-breuer-papers-5596/subseries-6-1/reel-5718-frames-936-954.

Breuer, M. and Blake, P. 1955. Marcel Breuer: Sun and Shadow, The Philosophy of an Architect, New York: Longmans, Green \& Company.

Gatje, R. F. 2006. Marcel Breuer, a memoir. New York: The Monacelli Press.

Hitchcock, H. R. 1938. "Marcel Breuer and the American Tradition in Architecture". Harvard University Archives. Marcel Breuer papers, 1920-1986. Box 34, Reel 5737, Frames 1053-1078, https://www.aaa.si.edu/collections/marcel-breuer-papers-5596/series-9/reel-5737-frames-1053-1078

Hyman, I. 2001. Marcel Breuer architect. The career and the buildings. New York: Harry N. Abrams.

Driller, J. 2000. Breuer houses. London: Phaidon Press Limited.

Jones, C. 1963. Marcel Breuer. Construcciones y proyectos 1921-1961. Barcelona: Editorial Gustavo Gili. 


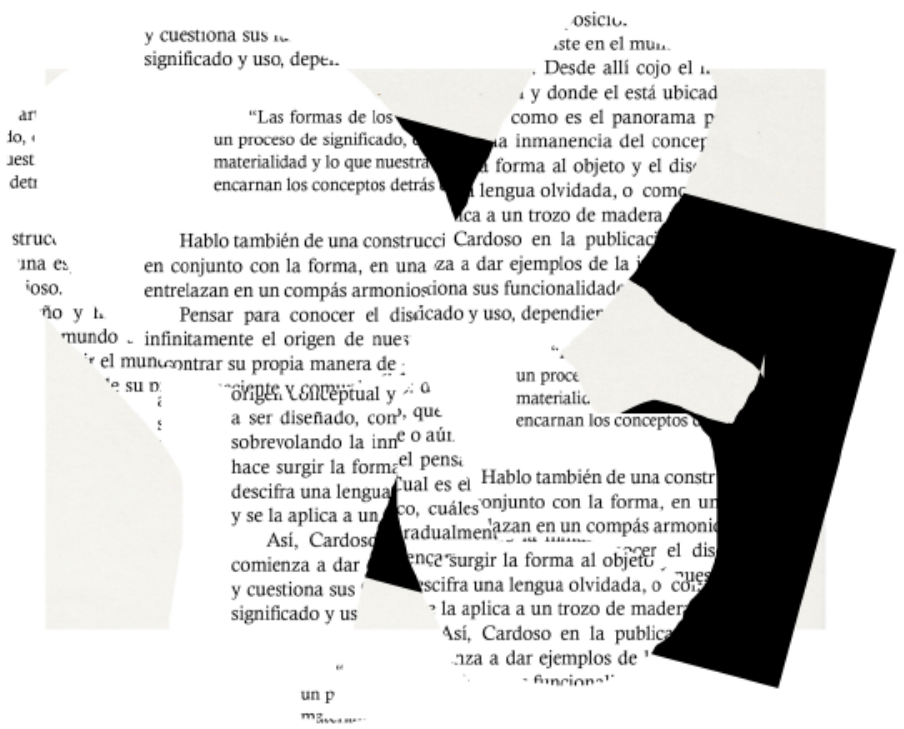

"Lo impreso exige una humildad de espíritu por cuya falta muchas de las bellas artes se tambalean ahora en experimentos de autoconciencia y sensiblería. No hay nada simple ni aburrido en lograr una página transparente. La ostentación vulgar es el doble de fácil que la disciplina".

Beatrice Warde, The Crystal Goblet, or why printings should be invisible (1930)

"El diseño que es objetivo, comprometido con el bien común, bien compuesto y delicado, constituye la base del comportamiento democrático".

Josef Müller-Brockmann, Grid and Design Philosophy (1981) 

EDITA

\section{SEyTA.}

SOCIEDAD ESPAÑLAA
DE ESTETICA Y TEORIA DE LAS ARTES

CON LA COLABORACIÓN DE

\begin{tabular}{|c|c|c|}
\hline 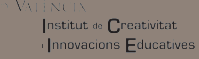 & $\begin{array}{l}\text { VNIVIRSIIA } \\
\text { In VVIIINCI Departament de Filosofia }\end{array}$ & 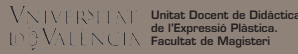 \\
\hline $\begin{array}{l}\text { TitTicA } \\
\text { SoFFA }\end{array}$ & 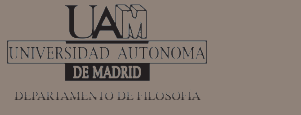 & $\begin{array}{l}\text { UAB } \\
\text { Universitat Autònoma } \\
\text { de Barcelona }\end{array}$ \\
\hline
\end{tabular}

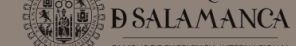

https://ojs.uv.es/index.php/LAOCOONTE/index 